\title{
Formation of a methodology for managing the strategic stability of transport enterprises
}

\author{
Svetlana Grigoreva* \\ Moscow State University of Civil Engineering, 129337, Moscow, Russia
}

\begin{abstract}
The article deals with the methodological aspects of the formation of a management system for the strategic stability of a transport company. The stages of the methodology formation are considered. A mathematical model for the strategic stability management system analysis has been built. The systematic formalization of strategic stability management is described.
\end{abstract}

\section{Introduction}

It is now more important than ever to successfully cope with changes in today's volatile and complex economic environment.

Transport, as a key component supporting interaction and development of socioeconomic systems, is an object of close attention.

Transport and mobility are critical to the sustainable development of society. Sustainable transport can foster economic growth, expand trade opportunities and improve accessibility. Sustainable, reliable and safe transport ensures better integration of the economy while preserving the environment.

In modern economic conditions, the strategic priority of a transport company is the development of an effective strategy for managing its sustainable development.

The main goal of management is to constantly improve the results of the enterprise continuous development.

The strategic stability of a transport enterprise is characterized by the absence of significant changes in the activities of the enterprise over a long period of time, taking into account the achievable development of the territory.

The concept of strategic sustainability is considered in the works of such scientists as T.V. Terentyeva [10], M.N. Dudin [3], N.A. Sabanchiev [8], S.P. Baranenko, V.V. Shemetov [2] and others.

The relevance of the research problem is due to the fact that the preservation of the upward trend in the development of an enterprise using modern management methods forces them to acquire knowledge and experience in the field of management while following the principles of sustainable development. Despite the growth prospects, transport enterprises have limitations in managing sustainable development. Therefore, the

\footnotetext{
* Corresponding author: GrigorevaSV2017@yandex.ru
} 
formation of a methodology for managing strategic stability is given priority in the sustainable development of an enterprise.

Various methodological aspects in frames of the enterprise management theory are considered in such works as: I. Ansoff [1], Mescon M. Kh., Albert M., Khedouri F. [6], Gerasimov B. N., Gerasimov K. B. [ 4], A. V. Zheltenkov. [5], Novikov A.M. [7], Tarasenko V.V. [9], Aguinis H., Boyd B.K., Pierce C.A., Short J.C. [11], Bin A., SallesFilhoa, S. [12] and others.

Methodological aspects of the strategic stability management system formation are not developed at the present time and are not widely represented in economic literature.

\section{Scheme of the methodology formation for managing strategic sustainability}

It is not enough for an enterprise to use standard management models to ensure a competitive advantage.

Therefore, each enterprise in the context of changes dynamism must form its own unique management system in accordance with strategic goals to ensure strategic sustainability growth.

The purpose of the management methodology is to provide the manager with the tools that will help ensure the successful implementation of the system that meets the strategic goals of the enterprise.

Let us consider the stages of the methodology formation for managing the strategic stability of a transport company.

Stage 1. Formation of a conceptual apparatus based on a systematic approach. This stage includes disclosing the content of the "transport stability" and "strategic stability" concepts, highlighting the systemic elements of strategic stability, expressed in the characteristics of time and space, disclosing the content of temporal and spatial stability.

Stage 2. Development of the strategic sustainability management concept. This stage provides the allocation of principles that predetermine the goal of creating an effective management system to ensure strategic stability growth, mechanisms of interaction between the subject and the object of management to achieve the set goal by the system, laws and management functions, components of the system and their functional tasks, as well as a criterion for the effectiveness of strategic stability management enterprises.

Stage 3. Determination of the modern development features of a transport company. At this stage, the systematization of strategic determinants is carried out, modeling of cargo turnover, identification of problems in the development of the enterprise.

Stage 4. Measuring the driving forces of strategic sustainability and translating them into indicators. At this stage, the systems of temporal and spatial stability indicators, a complex indicator of strategic stability, are formed.

Stage 5. Formalization of strategic sustainability management. At this stage, forms of management are identified, a model for choosing an enterprise development program is being developed, and the provisions of the theory of mine administration are being developed.

The development of a management methodology at the enterprise, taking into account innovative methods, creates the basis for a management system formation of a transport enterprise strategic stability.

Strategic sustainability integrates temporal sustainability (maintaining an upward trend) and spatial sustainability (achievable development of the territory) [13]. 


\section{Mathematical model of the strategic stability management system analysis}

By a process we mean a sequence of time-varying states of the strategic stability management system. A discrete process is characterized by an abrupt change in states. A continuous process has an infinite number of different states.

In a deterministic process, the final state is clearly defined by the initial state and the state due to the influences on the process.

The process is called controlled when the course of the process can be influenced.

Let us represent the management of strategic stability as a controlled deterministic continuous process, which at each moment of time $t$ is described by two state parameters (phase coordinates - time $Y_{v}(t)$ and spatial $Y_{p}(t)$ stability), which are the strategic stability state vector components $\mathbf{Y}_{s}(t)$

$$
\mathbf{Y}_{s}(t)=\left(Y_{v}(t), Y_{p}(t)\right)
$$

For each fixed $t$ vector a point is depicted, and for continuously changing time a trajectory in a two-dimensional phase space is described.

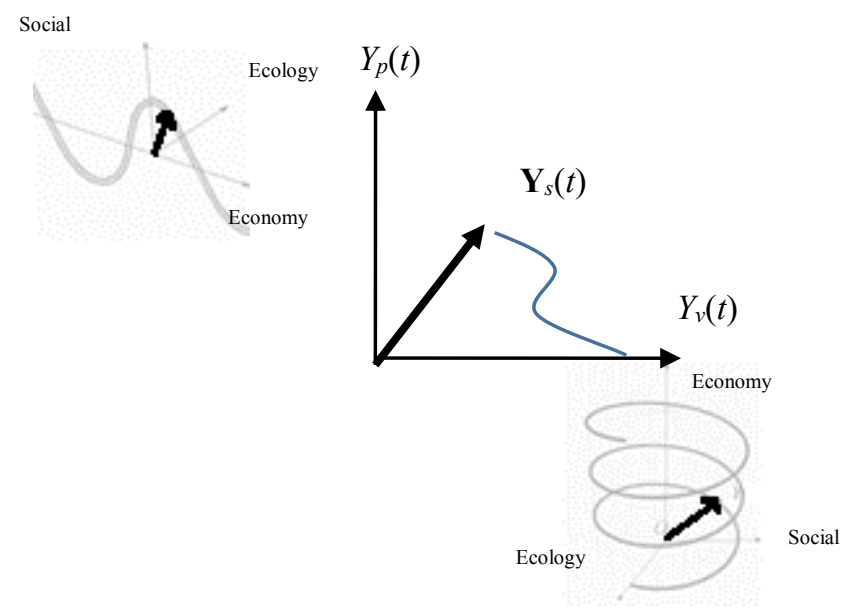

Fig. 1. The modern image of "strategic stability" concept

In addition, the process under consideration is characterized by $b$ control parameters (control functions) $u_{j}(t), j=1, \ldots, b$, which are the components of the control vector $\mathbf{U}(t)=\left(u_{1}(t), u_{2}(t), \ldots, u_{b}(t)\right)$.

The process is fully defined if the initial state of strategic sustainability and all of its management functions are known $u_{j}(t), j=1, \ldots, b$.

Since many processes, in principle, can be represented as a set of displacements, the relationships between phase coordinates in control systems are described using differential equations.

The quantity

$$
\frac{d \mathbf{Y}_{s}}{d t}=\mathbf{v}\left(\mathbf{Y}_{s}, t\right)
$$


describes the strategic resilience renewal rate.

Then for all given phase points $Y_{s(0)}, Y_{s(1)}$ among all admissible control vectors $\boldsymbol{U}(t), t$ belongs to the segment $\left[t_{0}, t_{1}\right]$, transferring the process from the state $Y_{s(0)}$ in $Y_{s(1)}$, the point is determined, the functional of which

$$
F(u)=\int_{t_{0}}^{t_{1}} \mathbf{v}\left(\mathbf{Y}_{s}, t\right) d t
$$

becomes minimal. Each control vector $\mathbf{U}(t)$ is optimal.

\section{Formalizing strategic sustainability management}

Formalization, in the broadest sense of the word, is defined as systematized rules, policies and procedures for the formation of governance.

Formalization of strategic stability management of road transport enterprises will consolidate the built-in management mechanisms. Formalization of management will help to clearly formulate the provisions of the theory of mine administration for strategic stability.

The theory of mine administration uses the concept of strategic sustainability management [13].

The theory of mine administration is a set of tools, methods, ideas, models, technologies that allow an enterprise to maintain an upward trend of development for a long time.

When building a theory of mine administration, it is necessary to fulfill a number of conditions, which we will formulate in the form of axioms:

1. availability of the control object observability;

2. availability of controllability;

3. the presence of a target subsystem;

4. availability of a supporting subsystem;

5. freedom of choice of control actions;

6. availability of management efficiency criterion;

7. availability of resources (natural, material, human, informational, financial, etc.) that ensure the control object functioning.

The subject of management is the top managers of the enterprise, the economic bureau, and the resource support department.

The object of management is the management system for the strategic stability of the enterprise.

Each system has its own life cycle. The life cycle of a system is a series of stages that are worked through when developing a new system. The system development life cycle is a multi-stage iterative process structured methodically.

The T-model of the life cycle of an enterprise strategic stability management system includes five main stages: system analysis and requirements; system design; development; implementation; accompaniment.

The first stage - System analysis and requirements - includes the enterprise mission formation, the definition of strategic goals for the enterprise development. It determines whether there is a need for a new strategic sustainability management system to achieve strategic objectives. At this stage, the enterprise must work on the source of its problem. Possible solutions are presented and analyzed to determine the most appropriate in order to achieve strategic sustainability. Systems analysis is vital to determine the needs for 
managing strategic sustainability, how they can be met, who will be responsible for the individual parts of the system, and how the enterprise roadmap will be formed.

The second stage - System design - describes in detail the necessary provisions, specifications, functions and operations that will correspond to the functional requirements of the proposed system that will be implemented.

The third stage - Development - at this stage, the system is developed taking into account the functional requirements identified at the previous stage, with the allocation of various forms of the enterprise strategic stability management.

The fourth stage - Implementation - which includes using the system in practice, monitoring the parameters of strategic stability, calculating a comprehensive indicator of strategic stability and subsequent analysis for the adequacy of the goal set at the first stage. This stage ensures the formation of the enterprise knowledge base.

The fifth stage - Maintenance - analysis of deviations is carried out and decisions are made on the choice of a possible development program.

To ensure the enterprise strategic stability growth, we distinguish various forms in management system.

Harmonious administration is a strategic sustainability management process based on the formation of a system of indicators of temporal and spatial sustainability, a complex indicator of strategic sustainability with its subsequent analysis and development of an expert system for choosing further actions.

Forward-looking administration is the process of predicting strategic resilience based on past events and future management information. The ability to predict results when using such tools as foresight, forecasting based on leading indicators, trend analysis of a complex indicator of strategic sustainability allows the enterprise to respond to threats, helps the enterprise in setting strategic goals. The validity of the development program choice depends on forecast accuracy.

Risk administration is a process aimed at reducing to an acceptable level of a value that characterizes a deviation from the set strategic goals in the development of an enterprise due to an incorrect assessment of economic, political, social, environmental factors and incorrect tactical and strategic decisions taken on this basis.

Transformational administration is the process of introducing information technologies into strategic sustainability management, namely, the creation of an information environment and the use of which provides information for building the architecture of a strategic sustainability management model.

Innovative administration is the process of promoting managerial innovations that are non-traditional for trucking enterprises, such as management by goals, customer relationship management, development of strategic maps, reengineering of business processes, budgeting with the definition of tasks and conditions for the implementation of each form of innovation in relation to a transport enterprise.

Digital administration is the process of creating, documenting, storing, transferring and applying all the knowledge of an enterprise in order to improve a comprehensive indicator of strategic sustainability.

\section{Conclusion}

Thus, it has been determined that the methodology formation for managing the strategic stability of an enterprise requires a significant amount of time and involves the development of a long-term comprehensive plan of measures aimed at increasing strategic stability, providing competitive advantages and strengthening its position in the existing market in accordance with the enterprise strategic mission and goals. If before the implementation of the strategic stability management system there is a fluctuation of the 
strategic stability complex indicator, then after implementation - the complex indicator is in its stability zone.

Summing up, we note the following. Strategic sustainability management for transport enterprises must be carried out within the framework of a systematic approach, taking into account the specifics of the industry using modern innovative management methods. The author believes that the considered methodological aspects of the strategic stability management system formation will provide the heads of transport enterprises with a vision of the enterprise strategic stability desired state.

\section{References}

1. I. Ansoff, Strategic management. Classic edition: translated from English (Peter, SPb., 2009)

2. S.P. Baranenko, V.V. Shemetov, The strategic stability of the enterprise (Polygraph, M., 2004)

3. M.N. Dudin, Ensuring the strategic sustainability of entrepreneurial structures in the context of innovative development, PhD Thesis abstract (Moscow, 2013)

4. B.N. Gerasimov, K.B. Gerasimov, Methodology of management (SIBiU, Samara, 2013)

5. A.V. Zheltenkov, Self-organizing management system: organization and methodology of creation (SUU, M., 2001)

6. M.Kh. Mescon, M. Albert, F. Hedouri, Fundamentals of management: translated from English 3rd edition (LLC "I.D. Williams ", Moscow, 2008)

7. A.M. Novikov, D.A. Novikov, Methodology (SIN-TEG, Moscow, 2007)

8. N.A. Sabanchiev, Theoretical and methodological foundations of organizational support for strategic sustainability, PhD thesis abstract (Moscow, 2009)

9. V.V. Tarasenko, Logic and methodology of management (Unity-Dana, Moscow, 2015)

10. T.V. Terentyeva, Methodological foundations for ensuring the sustainability of fishery business structures' development, $\mathrm{PhD}$ thesis (Vladivostok, 2011)

11. H. Aguinis, B.K. Boyd, C.A. Pierce, J.C. Short, Journal of Management 2, 395-403 (2011)

12. A. Bin, S. Salles-Filhoa, Journal of Technology Management and Innovation 2, 73-86 (2012)

13. S.V. Grigoreva, IOP Conference Series: Materials Science and Engineering 913 (4), 042011. 